\title{
Welding Metallurgy and Weldability of Superalloys
}

\author{
Joel Andersson (1) \\ Division of Welding Technology, Department of Engineering Science, University West, \\ SE-461 86 Trollhättan, Sweden; joel.andersson@hv.se; Tel.: +46-739-013-319
}

Received: 16 January 2020; Accepted: 17 January 2020; Published: 17 January 2020

\section{Introduction and Scope}

Fabrication and welding of structural superalloy components for aero-engines, land-based gas turbines as well as for the energy sector (i.e., steam boilers) continues to be of high importance to the manufacturing industry. The components, which utilize superalloys, are usually referred to as the most demanding, and where the welding of these most often plays an essential role, not only in manufacturing, but also in repair and re-manufacturing. It is therefore of utmost importance that the welds used in the design are of suitable quality to account for the demanding environment. Numerous challenges exist in welding these alloys and caution needs to be exercised in order to avoid problems such as hot cracking or strain age cracking. In addition, there is a wide range of weldability testing methods available to predict, for example, susceptibility toward hot cracking, where each method has its unique characteristics. Nevertheless, the available weldability testing methods play a vital role in the fundamental study of the root cause for weld cracking, which can be further enhanced by characterization as well as simulation. This Special Issue provides insight into new findings, communicating views about the accomplishments, and future directions in superalloy welding and weldability testing research.

\section{Contributions}

Researchers were invited to submit innovative research papers in the areas of welding metallurgy, weldability, and associated topics of superalloys. In total, six research papers were published in this Special Issue of Metals, entitled "Welding Metallurgy and Weldability of Superalloys", which presents some of the research trends in the field [1-6]. All six research papers were related to weld cracking in some aspect, with the strongest focus on hot cracking [1-4,6], followed by strain age cracking [5]. The major part of the submission in terms of material was associated with Alloy 718, the "work horse" within the group of superalloys in the aero-engine industry [2-4]. In addition, Haynes ${ }^{\circledR} 282^{\circledR}$, a superalloy that falls into the same class of superalloys (i.e. precipitation hardening $\mathrm{Ni}$ - or $\mathrm{Ni}-\mathrm{Fe}$ based superalloys) as Alloy 718 was covered in two papers that were investigated [5,6]. Varestraint weldability testing $[3,4,6]$ was the major testing method addressed within the field of weldability testing, followed by Gleeble thermomechanical testing [5]. Raza et. al. [2] investigated tungsten inert gas (TIG) welding on additive manufactured (AM, laser-powder bed fusion) Alloy 718 in different heat treatment conditions. The propensity for cracking in the heat affected zone (HAZ) were shown to be highest in the AM as-built condition and lowest in the AM hot isostatic pressed condition. A second paper by Raza et. al. [4] focused on the influence of grain orientation on the hot cracking susceptibility of AM Alloy 718 using Varestraint weldability testing. It was shown that cracks in the HAZ of the welded samples primarily took place in high angle grain boundaries with a smaller magnitude of cracking in the samples tested parallel to the elongated grain orientation compared to the tests performed transverse to the elongated grain orientation.

Another interesting contribution by Alvarez et. al. [3] investigated susceptibility toward hot cracking of wrought and investment cast Alloy 718 by the Varestraint weldability testing method. 
Testing was performed and compared on both TIG and laser beam welding (LBW). It was shown that the hot cracking susceptibility of LBW was enhanced due to extended center line hot cracking, resulting in a "fishbone" like cracking pattern. Only a minor effect was seen regarding the material form (wrought vs. cast), grain size, and pulsation. In fact, cast samples with coarse grain size had less susceptibility toward hot cracking than wrought material. Singh et. al. [6] studied Varestraint weldability testing as well as Gleeble thermomechanical simulation of the newly developed cast form of Haynes ${ }^{\circledR} 282^{\circledR}$ to understand how HAZ liquation cracking is influenced by different preweld heat treatments. It was found that cracking susceptibility did not improve with a higher degree of homogenization achieved at a higher heat treatment soak temperature, in contrast, cracking was exacerbated. The enhanced degree of cracking was related to B segregation at the grain boundaries, which at the highest heat treatment temperature of $1190^{\circ} \mathrm{C}$ indicated the liberation from the dissolution of $\mathrm{C}-\mathrm{B}$ rich precipitates.

Hanning et. al. [5] developed a Gleeble-based test method to study the change in the ductility signature of Haynes ${ }^{\circledR} 282^{\circledR}$ during isothermal exposure from $5 \mathrm{~s}$ to $1800 \mathrm{~s}$ within the temperature range of 750 to $950{ }^{\circ} \mathrm{C}$. Microstructural constituents (i.e. primary and secondary type carbides as well as hardening precipitates $\left(\gamma^{\prime}\right)$ were identified). A ductility minimum was observed at $800-850{ }^{\circ} \mathrm{C}$ and the fracture mode was found to be dependent on the stroke rate, where a transition toward intergranular fracture was observed for stroke rates below $0.055 \mathrm{~mm} / \mathrm{s}$. Intergranular fracture was identified by microvoids present on the grain facets, while ductility did not change during ongoing age-hardening reactions for intergranularly fractured Haynes ${ }^{\circledR} 282^{\circledR}$.

Chen et. al. [1] contributed with a paper on Ni-based weld fillers, IN52M and IN52MSS, where its weld performance on a stainless steel (SS) substrate was investigated [1]. The overlay-welding of IN52M and IN52MSS onto CF8A SS was conducted by a TIG welding process in multiple passes. Hot cracking of the overlay welds was shown to be related to the formation of $\gamma$-intermetallic $\left(\mathrm{Ni}_{3}(\mathrm{Nb}, \mathrm{Mo})\right)$ microconstituents. The greater contents of $\mathrm{Nb}$ and Mo in the 52MSS overlay enhanced the formation of these constituents at the interdendritic boundaries. Thus, the hot cracking sensitivity of the 52MSS overlay was higher than that of the $52 \mathrm{M}$ overlay.

\section{Conclusions and Outlook}

The Special Issue on "Welding Metallurgy and Weldability of Superalloys" presents a collection of research articles covering the relevant topics in the field. As Guest Editor, I hope that this collection of works may be useful to researchers working in the field, promoting more research studies, debates, and discussions that will continue to shed light and bridge the gap in understanding the real welding performance of superalloys using predictive weldability tests.

Acknowledgments: As Guest Editor, I would like to thank all who have contributed directly and indirectly to the successful development of this Special Issue. Thanks to all the authors who submitted their manuscripts and were willing to share the results of their research activities in this Special Issue. Special acknowledgements are due to the reviewers who agreed to revise the articles and provide feedback to improve the quality of the manuscripts. Credits should also be given to the editors and to the Assistant Editor Ms. Betty Jin as well as to all the staff of the Metals Editorial Office for their contribution and support in the publication process of this issue.

Conflicts of Interest: The author declares no conflicts of interest.

\section{References}

1. Chen, M.; Wu, T.; Chen, T.; Jeng, S.; Tsay, L. The Comparison of Cracking Susceptibility of IN52M and IN52MSS Overlay Welds. Metals 2019, 9, 651.

2. Raza, T.; Hurtig, K.; Asala, G.; Andersson, J.; Svensson, L.; Ojo, O. Influence of Heat Treatments on Heat Affected Zone Cracking of Gas Tungsten Arc Welded Additive Manufactured Alloy 718. Metals 2019, 9, 881. [CrossRef]

3. Alvarez, P.; Vázquez, L.; Ruiz, N.; Rodríguez, P.; Magaña, A.; Niklas, A.; Santos, F. Comparison of Hot Cracking Susceptibility of TIG and Laser Beam Welded Alloy 718 by Varestraint Testing. Metals 2019, 9, 985. [CrossRef] 
4. Raza, T.; Andersson, J.; Svensson, L. Varestraint Testing of Selective Laser Additive Manufactured Alloy 718-Influence of Grain Orientation. Metals 2019, 9, 1113. [CrossRef]

5. Hanning, F.; Khan, A.; Steffenburg-Nordenström, J.; Ojo, O.; Andersson, J. Investigation of the Effect of Short Exposure in the Temperature Range of $750-950{ }^{\circ} \mathrm{C}$ on the Ductility of Haynes ${ }^{\circledR} 282^{\circledR}$ by Advanced Microstructural Characterization. Metals 2019, 9, 1357. [CrossRef]

6. Singh, S.; Andersson, J. Heat-Affected-Zone Liquation Cracking in Welded Cast Haynes ${ }^{\circledR} 282{ }^{\circledR}$. Metals 2020, 10, 29. [CrossRef]

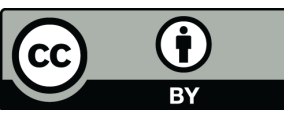

(C) 2020 by the author. Licensee MDPI, Basel, Switzerland. This article is an open access article distributed under the terms and conditions of the Creative Commons Attribution (CC BY) license (http://creativecommons.org/licenses/by/4.0/). 